\title{
Toxicidade da combinação de dióxido de carbono e fosfina sob diferentes temperaturas para Tribolium castaneum ${ }^{1}$
}

\author{
Raimundo W. S. Aguiar ${ }^{2,3}$, Lêda R. D'A. Faroni ${ }^{4}$, Raul N. C. Guedes ${ }^{3}$, Adalberto H. Sousa ${ }^{3}$ \& Adriano F. Rozado ${ }^{3}$
}

\begin{abstract}
RESU MO
0 objetivo deste trabal ho foi avaliar o efeito da temperatura sobre a toxicidade da combinação de dióxido de carbono e fosfina, para os estágios de desenvolvimento de Tribolium castaneum (H erbst) (Coleoptera: Tenebrionidae). A toxicidade da combinação de $5 \%$ de dióxido de carbono e $1 \mathrm{~g} \mathrm{~m}^{-3}$ de fosfina para os estágios de ovo, larvas de 5, 10 e 15 dias, pupa e adulto de T. castaneum, foi estudada nas temperaturas de $25,30,35,40$ e $45^{\circ} \mathrm{C}$, por meio de estimativas dos tempos de exposição letais para 50 e $95 \%$ dos insetos $\left(T_{50}\right.$ e $\left.T L_{95}\right)$. Curvas tempo-resposta foram estabelecidas mediante bioensaios com perío dos crescentes de exposição à combinação do dióxido de carbono com a fosfina. Observou-se que $05 \mathrm{TL}_{50}$ e $\mathrm{TL}_{95}$ reduziram com a elevação da temperatura em todos os estágios de T. castaneum avaliados. 0 estágio de larva de cinco dias foi a mais susceptível à combinação de dióxido de carbono e fosfina. De acordo com os resultados, a combinação do dióxido de carbono com a fosfina é alternativa potencial para diminuir a quantidade de fosfina aplicada em produtos armazenados, por apresentar alta toxicidade para todos os estágios de T. castaneum sob diferentes temperaturas.
\end{abstract}

Palavras-chave: armazenamento, fumigação, atmosfera modificada, inseto-praga

\section{Toxicity of the carbon dioxide and phosphine combination to Tribolium castaneum under different temperatures}

\begin{abstract}
The objective of this work was to assess the effect of temperature on the toxicity of the carbon dioxide-phosphine combination for the developmental stages of Tribolium castaneum (H erbst) (Coleoptera: Tenebrionidae). The toxicity of combination of $5 \%$ carbon dioxide and $1 \mathrm{~g} \mathrm{~m}^{-3}$ phosphine in the developmental stages of egg, lavae of 5, 10 and 15 days, pupae and adult of $\mathrm{T}$. castaneum was studied under the temperatures of $25,30,35,40$ and $45^{\circ} \mathrm{C}$, through the estimation of lethal insect exposure times of 50 and $95 \%\left(\mathrm{LT}_{50}\right.$ and $\left.\mathrm{LT}_{95}\right)$. For that, time-response curves were established through bioassays with increasing periods of exposure to the combination of carbon dioxide and phosphine. A reduction of $L T_{50}$ and $L T_{95}$ was observed with temperature increase in all developmental stages of $\mathrm{T}$. castaneum evaluated. The 5-day old larva was the developmental stage most susceptible to the combination of carbon dioxide and phosphine. According to the results, the combination of carbon dioxide with phosphine is a potential alternative to reduce the amount of phosphine applied on stored products, due to high toxicity in all developmental stages of T. castaneum under different temperatures.
\end{abstract}

Key w ords: storage, fumigation, modified atmosphere, insect-pest

1 Extraído da Dissertação de Mestrado apresentada pelo primeiro autor à U niversidade Federal de Viçosa, Viçosa, MG

2 Campus de Gurupi/UFT. Fone: (63) 3311-3516. E-mail: rwsa@uft.edu.br

3 DBA/UFV. Fone: (31) 3899-4008. E-mail: guedes@ufv.br; adalberto.sousa@ufv.br

4 DEA/UFV. 36570-000, Viçosa, MG. Fone: (31) 3899-1874. E-mail: Ifaroni@ufv.br; adrianorozado@oi.com.br 


\section{INTRODUÇÃO}

Tribolium castaneum (Herbst) (Coleoptera: Tenebrionidae) é um inseto-praga de produtos armazenados, encontrado em todo o território brasileiro. Apresenta hábito alimentar secundário e é cosmopolita, podendo atacar diferentes produtos, como farinhas, farelos, rações, grãos, biscoitos, etc (Trematerra \& Sciarretta, 2004; Daglish, 2006). Adultos de T. castaneum são os primeiros insetos a reinfestarem os produtos após o tratamento com inseticida, devido à sua grande habilidade de voo, especialmente em condições tropicais. Podem viver muitos meses, ou até anos, sob condições ótimas para o seu desenvolvimento $\left(35^{\circ} \mathrm{C}\right.$ e $75 \%$ UR) (Faroni \& Sousa, 2006).

A fosfina $\left(\mathrm{PH}_{3}\right)$ é o único fumigante utilizado no Brasil para controlar os insetos-praga de produtos armazenados. $\mathrm{O}$ uso contínuo e indiscriminado desde a década de 70 tem ocasionado, porém, o surgimento de populações resistentes em várias regiões do País (Lorini et al., 2007). Pimentel et al. (2007) constataram que uma população de $T$. castaneum coletada no município de Bom Despacho, MG, foi 186 vezes mais resistente que a população padrão de susceptibilidade, coletada no município de Água Boa, MT.

Uma alternativa para minimizar os problemas inerentes ao uso contínuo e indiscriminado da fosfina consiste na combinação deste fumigante com o dióxido de carbono. Embora não considerado um fumigante, o dióxido de carbono, quando em altas concentrações, é reconhecidamente tóxico aos insetos (Noomhorm et al., 2009). Fields \& White (2002) demonstraram que o $\mathrm{CO}_{2}$ é tóxico para pragas de grãos armazenados durante longos períodos em níveis produzidos pela própria respiração dos insetos. Sabe-se, entretanto, que são necessárias dosagens elevadas de dióxido de carbono para se obter o controle efetivo de insetos (Gunasekaran \& Rajendran, 2005). Apesar do tempo de exposição dos grãos ao dióxido de carbono ou à combinação deste com a fosfina ser longo, esses gases não alteram a qualidade dos produtos tratados (Faroni et al., 2002).

A associação de dióxido de carbono com fosfina tem sido recomendada com a finalidade de reduzir tanto a concentração necessária de ambos quanto o tempo de exposição necessário para se obter o controle efetivo dos insetos (Casella et al., 1998; Martinazzo et al., 2000). Em estudo visando avaliar a eficácia da combinação de fosfina $\left(0,23 \mathrm{~g} \mathrm{~m}^{-3}\right)$ e dióxido de carbono (4 a 6\%) para diferentes estágios de desenvolvimento de Sitophilus oryzae (L.) (Coleoptera: Curculionidae), Mueller (1994) verificou que o controle efetivo dos adultos (100\% de mortalidade) foi obtido no período de $12 \mathrm{~h}$; para os estágios de ovo, larva e pupa, o controle efetivo foi obtido no período de $24 \mathrm{~h}$. O uso da combinação da fosfina nas doses de 0,50 e $0,75 \mathrm{~g} \mathrm{~m}^{-3}$, com uma atmosfera rica em dióxido de carbono $\left(21 \%\right.$ de $\left.\mathrm{CO}_{2}\right)$, no período de exposição de $120 \mathrm{~h}$, resultou na mortalidade efetiva (100\%) para todos os estágios de desenvolvimento de $S$. zeamais Motsch. (Casella et al., 1998) e Rhyzopertha dominica (F.) (Coleoptera: Bostrichidae) (Martinazzo et al., 2000). Nesses estudos, ovos e adultos foram os estágios mais susceptíveis para as duas espécies.

Embora a toxicidade da combinação da fosfina com o di- óxido de carbono seja conhecida para insetos-praga de produtos armazenados, pouco se sabe sobre os fatores bióticos e abióticos que podem interferir na eficácia de sua aplicação. Em geral, a toxicidade dos fumigantes apresenta relação direta com a temperatura ambiente e com o estágio de desenvolvimento dos insetos (Pereira et al., 2008). Do ponto de vista biológico, os estágios de desenvolvimento e as temperaturas que proporcionam maior atividade metabólica nos insetos, os tornam mais passíveis à ocorrência de desbalanços nas trocas gasosas em função da atividade dos inseticidas (Pimentel et al., 2009). Isto ocasiona maior gasto energético para a manutenção da homeostase, que é o processo responsável pela manutenção da integridade do ambiente interno das células (Nation, 2002; Sousa et al., 2008).

A temperatura também interfere na distribuição dos fumigantes podendo afetar sua eficácia no controle de insetos (Pratt $\&$ Reuss, 2004). Em temperaturas abaixo de $15,6{ }^{\circ} \mathrm{C}$, a distribuição dos fumigantes é menos uniforme na massa de grãos uma vez que, nessas condições, os gases apresentam baixa volatilidade e são mais adsorvidos pelos grãos, podendo resultar no aumento da dose ou do período de exposição necessário para controlar os insetos (Chaudhry et al., 2004; Pereira et al., 2007). Por outro lado, com a elevação da temperatura os gases se difundem mais rapidamente pela massa de grãos e os insetos respiram mais, absorvendo maior quantidade de inseticidas (Hulasare et al., 2005; Sousa et al., 2008).

Objetivo neste trabalho avaliar o efeito da temperatura sobre a toxicidade da combinação de dióxido de carbono e fosfina para os estágios de desenvolvimento de T. castaneum.

\section{MATERIAL E MÉTODOS}

Os experimentos foram realizados no Setor de Preprocessamento e Armazenamento de Produtos Agrícolas do Departamento de Engenharia Agrícola da Universidade Federal de Viçosa (UFV).

\section{Criação dos insetos}

A criação de $T$. castaneum foi feita em grãos de trigo semitriturados, mantidos em câmaras climáticas tipo B O D, sob condições constantes de temperatura $\left(30 \pm 2{ }^{\circ} \mathrm{C}\right)$, umidade relativa $(70 \pm 5 \%$ ) e escotofase de $24 \mathrm{~h}$. Para obtenção dos estágios de ovo, larvas de 5, 10 e 15 dias, pupa e adulto de $T$. castaneum, 200 insetos adultos foram postos em frascos plásticos de $95 \mathrm{~mm}$ de diâmetro e $100 \mathrm{~mm}$ de altura, contendo $150 \mathrm{~g}$ de grãos de trigo semitriturado. Após cinco dias se coletaram ovos para os bioensaios de toxicidade e para obtenção dos demais estágios. Os ovos coletados para se obter os demais estágios foram colocados em placas de Petri de $140 \mathrm{~mm}$ de diâmetro e $10 \mathrm{~mm}$ de altura, contendo $35 \mathrm{~g}$ de grãos de trigo semitriturados. Conhecendo-se a data de coleta dos ovos e o ciclo biológico de T. castaneum, obtiveramse os três estágios larval, pupa e adulto, segundo Casella et al. (1998) e Martinazzo et al. (2000).

\section{Obtenção da atmosfera modificada}

A combinação de $5 \%$ de dióxido de carbono e $1 \mathrm{~g} \mathrm{~m}^{-3}$ de 
fosfina foi realizada no interior de três câmaras metálicas com volume interno de $1 \mathrm{~m}^{-3}$. Em cada câmara havia uma abertura lateral para manipulação dos insetos e das pastilhas de fosfeto de alumínio. As câmaras tinham, ainda, duas conexões, a primeira contendo uma válvula para injeção de gases e a outra com válvula de segurança.

Em todos os bioensaios a concentração de $1 \mathrm{~g} \mathrm{~m}^{-3}$ de fosfina foi obtida através da reação do fosfeto de alumínio com a água presente no ar atmosférico do interior das câmaras, a partir de pastilhas de $3 \mathrm{~g}$ de fosfeto de alumínio (AlP). Com relação ao $\mathrm{CO}_{2}$, sua concentração de $5 \%$ foi obtida através da injeção direta de $\mathrm{CO}_{2}$ (com grau de pureza mínimo de $99,8 \%$ ), após a vedação das câmaras. A concentração do gás foi verificada pelo analisador de $\mathrm{CO}_{2}$ (modelo $425 \mathrm{~N}$, da marca NOVA Analytical Systems Inc) acoplado às câmaras. Em todos os bioensaios, quando o percentual de $5 \%$ de $\mathrm{CO}_{2}$ dentro das câmaras metálicas era estabelecido, interrompiase a injeção, fechando-se as válvulas de injeção e de segurança. $\mathrm{O}$ controle foi constituído de ar atmosférico (78\% de $\mathrm{N}_{2}, 0,03 \%$ de $\mathrm{CO}_{2}$ e $21 \%$ de $\mathrm{O}_{2}$ ) para cada temperatura e estágio de desenvolvimento de $T$. castaneum.

\section{Bioensaios de tempo-resposta}

Inicialmente se estimaram, para cada temperatura e estágio de desenvolvimento, os períodos de exposição da atmosfera modificada, necessários para matar o menor número de insetos (mortalidade semelhante ao controle) e os períodos de exposição em que a mortalidade dos insetos fosse próxima de $100 \%$. A partir dos valores obtidos nesses testes se estabeleceram os períodos de exposição intermediários. Os dados de mortalidade foram utilizados para gerar curvas de tempo-mortalidade obtendo-se, assim, os tempos letais para 50 e $95 \%$ de mortalidade $\left(\mathrm{TL}_{50}\right.$ e $\left.\mathrm{TL}_{95}\right)$ para cada estágio e temperatura.

As unidades experimentais foram constituídas de copos plásticos de $70 \mathrm{~mm}$ de diâmetro e $90 \mathrm{~mm}$ de altura contendo $30 \mathrm{~g}$ de trigo semitriturados e 20 insetos. Utilizaram-se três repetições. Todos os tratamentos foram iniciados somente após a estabilização de cada temperatura. Avaliou-se a mortalidade dos adultos após $12 \mathrm{~h}$ do término de cada teste; para os demais estágios, a avaliação da mortalidade foi realizada a cada dez dias até se obter o tempo necessário para os insetos dos estágios de ovo, larvas de 5,10 e 15 d e as pupas se tornarem adultos.

\section{Análise estatística}

Os resultados dos bioensaios de tempo-resposta foram submetidos a análise de probit utilizando-se o procedimento PROBIT do software SAS (SAS Institute, 1989). Adicionalmente, análises de regressão foram realizadas em função da temperaura para cada estágio de desenvolvimento estudado, utilizando-se curvas do software SigmaPlot, versão 7.0 (SPSS, 2001).

\section{RESULTADOS E DISCUSSÃO}

Os $\mathrm{TL}_{50}$ e $\mathrm{TL}_{95}$ para as temperaturas e estágios de desenvolvimento de T. castaneum são apresentados na Tabela 1.
Os $\mathrm{TL}_{50}$ nas temperaturas de $25,30,35,40$ e $45{ }^{\circ} \mathrm{C}$ variaram, respectivamente, de 10,99 a 18,85 h para ovos; de 5,11 a 14,27 h para larvas de cinco dias; de 10,02 a 18,53 h para larvas de dez dias; de 10,10 a 20,12 h para larvas de 15 dias; de 12, 21 a 18,79 h para pupas e de 11,33 a 19,51 h para adultos. Para os $\mathrm{TL}_{95}$, esta variação foi de 20,55 a $35,27 \mathrm{~h}$ para ovos; de 11,97 a 27,42 h para larvas de cinco dias; de 17,02 a 30,68 h para larvas de dez dias; de 18,70 a $32,87 \mathrm{~h}$ para larvas de 15 dias; de 21,55 a 34,32 h para pupas e de 17,75 a $39,34 \mathrm{~h}$, para adultos.

De acordo com as análises de regressão linear $(Y=a+b x)$, os $\mathrm{TL}_{50}$ e $\mathrm{TL}_{95}$ reduziram significativamente com a elevação da temperatura em todos os estágios avaliados (Tabela 2). Observa-se, na Tabela 1, que esta redução foi mais expressiva nas larvas de cinco dias, para as quais os $\mathrm{TL}_{50}$ da temperatura de $45{ }^{\circ} \mathrm{C}$ reduziram de 64,19 a $51,33 \%$ em relação às temperaturas de 25 a $45^{\circ} \mathrm{C}$. Tal redução para os $\mathrm{TL}_{95}$ foi de 56,34 a $30,40 \%$. Ressalta-se que na temperatura de $45^{\circ} \mathrm{C}$ os intervalos de confiança dos $\mathrm{TL}_{50}$ e $\mathrm{TL}_{95}$ para as larvas de cinco dias não se sobrepuseram aos intervalos de confiança dos demais estágios, ao contrário do que foi observado nas temperaturas de 25 a $40{ }^{\circ} \mathrm{C}$; então, o estágio de larva de cinco dias apresenta maior susceptibilidade à combinação do dióxido de carbono com fosfina que os estágios de ovo, larvas de 10 e 15 dias, pupa e adulto, diferença esta maior na temperatura de $45^{\circ} \mathrm{C}$.

Como a principal rota de entrada dos fumigantes nos insetos é o sistema respiratório, fatores associados à sua atividade respiratória, como a temperatura, podem afetar a captação dos fumigantes (Chaudhry et al., 2004; Mitcham et al., 2006). Desta forma, o aumento da toxicidade da combinação do dióxido de carbono e fosfina com a elevação da temperatura pode ter ocorrido em virtude do aumento da taxa respiratória dos insetos tendo, como consequência, uma captação maior das moléculas inseticidas.

A maior toxicidade da combinação dióxido de carbono com a fosfina para o estágio de larva de cinco dias, também pode estar associada à taxa respiratória uma vez que este é o estágio de T. castaneum que apresenta maior taxa respiratória em algumas espécies de insetos-praga de produtos armazenados. Emekci et al. (2002) observaram que a taxa respiratória de ovos, larvas jovens e velhas, pupas e adultos de T. castaneum a $30{ }^{\circ} \mathrm{C}$, e sob condições normais de ar atmosférico, foi de 0,32 ; 29,08; 3,33; 0,59 e 2,37 $\mu \mathrm{l} \mathrm{CO}_{2} \mathrm{mg}$ inseto $\mathrm{h}^{-1}$, respectivamente. Diferentes padrões respiratórios também foram observados entre os estágios de desenvolvimento de Rhyzopertha dominica (F.) (Coleoptera: Bostrichidae) (Emekci et al., 2004) que, por sua vez, teve a taxa respiratória para os estágios de ovo, larva jovem e velha, pupa e adulto a $30{ }^{\circ} \mathrm{C}$, sob condições normais de ar atmosférico, de 0,14; 4,83; 1,98; 0,64 e 2,58 $\mu 1$ $\mathrm{CO}_{2} \mathrm{mg}^{-1}$ inseto $\mathrm{h}^{-1}$, respectivamente.

As respostas diferenciadas entre os estágios de desenvolvimentos dos insetos-praga de produtos armazenados para os fumigantes também podem estar relacionadas à produção de proteínas de defesa (Mahroof et al., 2003; 2005). Algumas proteínas, como chaperonas, estão relacionadas com a proteção celular sob condições de estresse (Ojima et al., 2005). As chaperonas são conhecidas pelo seu papel na proteção das proteínas presentes nas membranas celulares e interagem com outras 
Tabela 1. Tempos letais ( $\mathrm{TL}_{50} \mathrm{e} \mathrm{TL}_{95}$ ) da atmosfera modificada com $5 \%$ de dióxido de carbono e $1 \mathrm{~g} \mathrm{~m}$-3 de fosfina para os estáaios de desenvolvimento de Tribolium castaneum

\begin{tabular}{|c|c|c|c|c|c|c|}
\hline Estágio & Temperatura $\left({ }^{\circ} \mathrm{C}\right)$ & Inclinação \pm E.P.M. & $\mathrm{TL}_{50}$ (IF 95\%) h & $\mathrm{TL}_{95}$ (IF 95\%) h & $\chi^{2}$ & $\mathbf{P}$ \\
\hline \multirow{5}{*}{ Ovo } & 25 & $1,80 \pm 0,13$ & $18,85(17,36-20,19)$ & $35,27(30,18-38,19)$ & 2,00 & 0,57 \\
\hline & 30 & $1,84 \pm 0,11$ & $15,71(12,29-18,28)$ & $29,72(26,66-34,81)$ & 3,29 & 0,34 \\
\hline & 35 & $1,70 \pm 0,09$ & $14,81(14,49-17,01)$ & $26,50(22,04-32,08)$ & 6,29 & 0,46 \\
\hline & 40 & $1,99 \pm 0,15$ & $12,65(11,82-13,42)$ & $21,25(19,45-24,04)$ & 6,07 & 0,10 \\
\hline & 45 & $1,64 \pm 0,07$ & $10,99(10,09-11,84)$ & $20,55(18,97-25,37)$ & 7,45 & 0,86 \\
\hline \multirow{5}{*}{ Larva (5 dias) } & 25 & $1,84 \pm 0,09$ & $14,27(13,25-15,26)$ & $27,42(24,31-32,72)$ & 4,18 & 0,24 \\
\hline & 30 & $2,07 \pm 0,12$ & $13,38(11,28-14,07)$ & $21,05(19,37-23,67)$ & 6,13 & 0,10 \\
\hline & 35 & $1,83 \pm 0,12$ & $12,22(10,29-15,21)$ & $20,85(19,03-23,70)$ & 1,99 & 0,57 \\
\hline & 40 & $2,35 \pm 0,14$ & $10,50(8,52-12,32)$ & $17,20(16,09-26,04)$ & 7,14 & 0,11 \\
\hline & 45 & $1,19 \pm 0,04$ & $5,11(4,57-6,12)$ & $11,97(10,46-14,45)$ & 5,73 & 0,22 \\
\hline \multirow{5}{*}{ Larva (10 dias) } & 25 & $1,98 \pm 0,10$ & $18,53(17,68-20,10)$ & $30,68(28,09-36,29)$ & 5,47 & 0,14 \\
\hline & 30 & $1,78 \pm 0,10$ & $17,61(16,28-18,38)$ & $30,53(27,94-34,97)$ & 3,32 & 0,22 \\
\hline & 35 & $1,78 \pm 0,10$ & $15,61(15,18-18,83)$ & $26,30(25,94-34,97)$ & 4,32 & 0,22 \\
\hline & 40 & $1,85 \pm 0,13$ & $13,6(11,28-15,36)$ & $24,20(22,56-27,02)$ & 9,52 & 0,48 \\
\hline & 45 & $2,14 \pm 0,16$ & $10,02(8,54-13,20)$ & $17,02(16,70-20,10)$ & 3,93 & 0,26 \\
\hline \multirow{5}{*}{ Larva (15 dias) } & 25 & $1,94 \pm 0,08$ & $20,12(18,00-21,58)$ & $32,87(29,66-36,91)$ & 3,13 & 0,37 \\
\hline & 30 & $1,84 \pm 0,11$ & $19,04(17,77-19,59)$ & $32,00(27,00-34,48)$ & 6,09 & 0,10 \\
\hline & 35 & $1,97 \pm 0,13$ & $16,62(15,36-17,78)$ & $28,17(26,05-31,51)$ & 1,81 & 0,61 \\
\hline & 40 & $1,67 \pm 0,13$ & $15,20(14,73-17,50)$ & $25,21(24,50-31,21)$ & 2,93 & 0,40 \\
\hline & 45 & $2,23 \pm 0,17$ & $10,10(9,19-13,51)$ & $18,70(16,20-19,00)$ & 2,80 & 0,42 \\
\hline \multirow{5}{*}{ Pupa } & 25 & $1,77 \pm 0,06$ & $18,79(14,54-21,91)$ & $34,32(26,25-37,78)$ & 2,92 & 0,40 \\
\hline & 30 & $1,94 \pm 0,08$ & $16,93(15,76-18,01)$ & $33,6(26,64-36,65)$ & 1,36 & 0,71 \\
\hline & 35 & $1,91 \pm 0,07$ & $16,33(15,29-17,29)$ & $28,6(25,65-31,15)$ & 7,60 & 0,54 \\
\hline & 40 & $2,05 \pm 0,09$ & $15,75(14,75-17,79)$ & $25,81(23,83-28,42)$ & 4,95 & 0,17 \\
\hline & 45 & $2,31 \pm 0,17$ & $12,21(10,89-14,90)$ & $21,55(19,56-27,56)$ & 2,80 & 0,42 \\
\hline \multirow{5}{*}{ Adulto } & 25 & $1,78 \pm 0,09$ & $19,51(18,33-22,62)$ & $39,34(33,31-43,40)$ & 1,52 & 0,67 \\
\hline & 30 & $1,55 \pm 0,05$ & $17,27(16,72-19,78)$ & $37,13(33,78-49,93)$ & 1,81 & 0,84 \\
\hline & 35 & $1,83 \pm 0,10$ & $15,54(14,68-17,23)$ & $28,53(24,21-31,36)$ & 4,21 & 0,23 \\
\hline & 40 & $1,86 \pm 0,10$ & $13,38(11,20-15,20)$ & $25,34(24,10-29,97)$ & 2,90 & 0,40 \\
\hline & 45 & $2,21 \pm 0,15$ & $11,33(10,20-13,29)$ & $17,75(16,23-19,09)$ & 2,12 & 0,54 \\
\hline
\end{tabular}

E.P.M. - erro padrão da média, TL - tempo letal, IF - Intervalo fiducial a $95 \%$ de probabilidade, $\chi^{2}$ - Qui-quadrado e $P$ - probabilidade

Tabela 2. Sumário das análises de regressão linear $(Y=a+b x)$ para a influência da temperatura sobre a toxicidade da combinação de dióxido de carbono e fosfina, para os estágios de desenvolvimento de Tribolium castaneum

\begin{tabular}{|c|c|c|c|c|c|c|c|}
\hline & \multirow{2}{*}{ Estágio } & \multicolumn{2}{|c|}{ Parâmetros estimados } & \multirow{2}{*}{ g.l eerro } & \multirow{2}{*}{$\mathbf{F}$} & \multirow{2}{*}{$\mathbf{P}$} & \multirow{2}{*}{$\mathbf{R}^{2}$} \\
\hline & & $a$ & $\mathbf{b}$ & & & & \\
\hline \multirow{6}{*}{$\mathrm{TL}_{50}$} & Ovo & $27,74 \pm 1,24$ & $-0,37 \pm 0,03$ & 3 & 116,98 & $<0,01$ & 0,97 \\
\hline & Larva (5 dias) & $25,93 \pm 3,64$ & $-0,42 \pm 0,10$ & 3 & 17,29 & 0,02 & 0,85 \\
\hline & Larva (10 dias) & $29,79 \pm 1,91$ & $-0,42 \pm 0,05$ & 3 & 61,65 & $<0,01$ & 0,95 \\
\hline & Larva (15 dias) & $32,93 \pm 2,85$ & $-0,47 \pm 0,07$ & 3 & 35,70 & $<0,01$ & 0,92 \\
\hline & Pupa & $26,04 \pm 2,11$ & $-0,28 \pm 0,05$ & 3 & 23,53 & $<0,01$ & 0,88 \\
\hline & Adulto & $29,73 \pm 0,32$ & $-0,41 \pm 0,01$ & 3 & $2.026,15$ & $<0,01$ & 0,99 \\
\hline \multirow{6}{*}{$\mathrm{TL}_{95}$} & Ovo & $53,19 \pm 3,29$ & $-0,75 \pm 0,09$ & 3 & 67,31 & $<0,01$ & 0,95 \\
\hline & Larva (5 dias) & $44,02 \pm 3,68$ & $-0,69 \pm 0,10$ & 3 & 45,34 & $<0,01$ & 0,93 \\
\hline & Larva (10 dias) & $49,30 \pm 4,67$ & $-0,67 \pm 0,13$ & 3 & 26,45 & $<0,01$ & 0,89 \\
\hline & Larva (15 dias) & $51,98 \pm 3,85$ & $-0,70 \pm 0,10$ & 3 & 42,32 & $<0,01$ & 0,93 \\
\hline & Pupa & $52,10 \pm 2,59$ & $-0,66 \pm 0,07$ & 3 & 84,13 & $<0,01$ & 0,96 \\
\hline & Adulto & $68,09 \pm 3,93$ & $-1,09 \pm 0,11$ & 3 & 99,48 & $<0,01$ & 0,97 \\
\hline
\end{tabular}

Todos os parâmetros estimados foram significativos a $\mathrm{P}<0,01$ pelo teste t-Student

proteínas celulares para garantir o estado normal de dobramento e minimizar a agregação de proteínas celulares em altas temperaturas (Heredia-Middleton et al., 2008). O aumento da produção das chaperonas em insetos sob condições de estresse foi observado para várias espécies, como T. castaneum, Papilio glaucus (L.); Manduca sexta (L.) (Fittinghoff \& Riddiford,
1988); Sarcophaga crassipalpis Macquart (Joplin \& Denlinger, 1990); Spathosternum prasiniferum (Walker); Periplaneta americana (L.) e Heliothis armigera (Hübner) (Singh \& Lakhotia, 2000). Desta forma, as respostas diferenciadas entre os estágios de $T$. castaneum podem estar associadas à menor produção de proteínas de defesa nas larvas de cinco dias. 
Adicionalmente a outros trabalhos em que é apresentado o potencial da combinação do dióxido de carbono com a fosfina, como fumigante (Casella et al., 1998; Martinazzo et al., 2000; Faroni et al., 2002), verificou-se, neste estudo, que tal fumigante poderá tornar-se uma alternativa aos inseticidas convencionais em regiões de clima tropical. Considerandose os elevados níveis de resistência à fosfina em insetos-praga de produtos armazenados no Brasil (Lorini et al., 2007; Pimentel et al., 2007; 2009) e o potencial de uso desta combinação em altas temperaturas, pode-se inferir que referida combinação é uma importante alternativa para ser utilizada nos programas de manejo de resistência a fosfina. Uma das prerrogativas para diminuir a velocidade de estabelecimento de populações com alta frequência de genes que conferem resistência a determinado agente de controle, é o emprego de mistura de inseticidas, uso alternado ou em mosaico de dois ou mais inseticidas (Sousa et al., 2008). Com o uso de diferentes agentes de controle os genótipos resistentes apresentam desvantagem reprodutiva na ausência do agente seletivo, permitindo o aumento da frequência dos genótipos suscetíveis (Kolaczinski \& Curtis, 2004).

\section{CONCLUSÕES}

1. A temperatura influenciou a toxicidade da combinação de dióxido de carbono e fosfina para todos os estágios de desenvolvimento de $T$. castaneum avaliadas.

2. A toxicidade da combinação de dióxido de carbono e fosfina foi mais substancial nas larvas de cinco dias.

3. A combinação do dióxido de carbono com a fosfina é alternativa potencial ao uso dos inseticidas convencionais em regiões de clima tropical.

\section{LITERATURA CITADA}

Casella, T. L. C.; Faroni, L. R. D’A.; Berbert, P. A.; Cecon, P. R. Dióxido de carbono associado à fosfina no controle do gorgulho-do-milho (Sitophilus zeamais). Revista Brasileira de Engenharia Agrícola e Ambiental, v.2, n.2, p.179-185, 1998.

Chaudhry, M. Q.; Bell, H. A.; Savvidou, N.; MacNicoll, A. D. Effect of low temperatures on the rate of respiration and uptake of phosphine in different life stages of the cigarette beetle Lasioderma serricorne (F.). Journal of Stored Products Research, v.40, n.2, p.125-134, 2004.

Daglish, G. J. Survival and reproduction of Tribolium castaneum (Herbst), Rhyzopertha dominica (F.) and Sitophilus oryzae (L.) following periods of starvation. Journal of Stored Products Research, v.42, n.3, p.328-338, 2006.

Emekci, M.; Navarro, S.; Donahaye, E.; Rindner, M.; Azrieli, A. Respiration of Tribolium castaneum (Herbst) at reduced oxygen concentrations. Journal of Stored Products Research, v.38, n.5, p.413-425, 2002.

Emekci, M.; Navarro, S.; Donahaye, E.; Rindner, M.; Azrieli, A. Respiration of Rhyzopertha dominica (F.) at reduced oxygen concentrations. Journal of Stored Products Research, v.40, n.1, p.27-38, 2004.
Faroni, L. R. D’A.; Berbert, P. A.; Martinazzo, A. P.; Coelho, E. M. Qualidade da farinha obtida de grãos de trigo fumigados com dióxido de carbono e fosfina. Revista Brasileira de Engenharia Agrícola e Ambiental, v.6, n.2, p.354-357, 2002.

Faroni, L. R. D’A.; Sousa, A. H. Aspectos biológicos e taxonômicos dos principais insetos-praga de produtos armazenados. In: Almeida, F. de A. C.; Duarte, M. E. M.; Mata, M. E. R. M. C. Tecnologia de Armazenagem em sementes, Campina Grande: UFCG, 2006. Cap.7, p.371-402.

Fields, P. G.; White, N. D. G. Alternatives to methyl bromide treatments for stored-product and quarantine insects. Annual Review of Entomology, v.47, n.1, p.331-359, 2002.

Fittinghoff, G. M.; Riddiford, L. M. Effect of heat shock on nonheat shock proteins of the insect integument. Journal of Cellular Biochemistry, v.12D, p.264-268, 1988.

Gunasekaran, N.; Rajendran, S. Toxicityof carbon dioxide to drugstore beetle Stegobium paniceum and cigarette beetle Lasioderma serricorne. Journal of Stored Products Research, v.41, p.283-294, 2005.

Heredia-Middleton, P.; Brunelli, J.; Drew, R. E.; Thorgaard, G. H. Heat shock protein (HSP70) RNA expression differs among rainbow trout (Oncorhynchus mykiss) clonal lines. Comparative Biochemistry and Physiology Part B: Biochemistry and Molecular Biology, v.149, n.4, p.552-556, 2008.

Hulasare, R. B.; White, N. D. G.; Jayas, D. S. Effect of suboptimal temperatures and sublethal $\mathrm{CO}_{2}$ levels on multiplication of Tribolium castaneum (Coleoptera: Tenebrionidae), alone or competing with Cryptolestes ferrugineus (Coleoptera: Cucujidae). Journal of Stored Products Research, v.41, n.2, p.187-197, 2005.

Joplin, K. H.; Denlinger, D. L. Developmental and tissue specicific control of the heat shock induced $70 \mathrm{kDa}$ related proteins in the flesh fly, Sarcophaga crassipalpis. Journal of Insect Physiology, v.36, n.4, p.239-249, 1990.

Kolaczinski, J. H.; Curtis, C. F. Investigation of negative crossresistance as a resistance-management tool for insecticidetreated nets. Journal of Medical Entomology, v.41, n.5, p.390-934, 2004.

Lorini, I.; Collins, P. J.; Daglish, G. J.; Nayak, M. K.; Pavic, H. Detection and characterization of strong resistance to phosphine in Brazilian Rhizopertha dominica (F.) (Coleoptera: Bostrychidae). Pest Management Science, v.63, n.4, p.358-364, 2007.

Mahroof, R.; Subramanyam, B.; Eustace, D. Temperature and relative humidity profiles during heat treatment of mills and its efficacy aginst Tribolium castaneum (Herbst) life estage. Journal of Stored Products Research, v.39, n.5, p.555-569, 2003.

Mahroof, R.; Zhu, Y. K.; Subramanyam, B. Changes in expression of heat-shock proteins in Tribolium castaneum (Coleoptera: Tenebrionidae) in relation to developmental stage, exposure time, and temperature. Annals of the Entomological Society of America, v.98, n.1, p.100-107, 2005.

Martinazzo, A.; Faroni, L. R. D’A.; Berbert, P. A.; Reis, F. P. Utilização da fosfina em combinação com o dióxido de carbono no controle do Rhyzopertha dominica (F.). Pesquisa Agropecuária Brasileira, v.35, n.6, p.1063-1069, 2000.

Mitcham, E.; Martin, T.; Zhou, S. The mode of action of insecticidal controlled atmospheres. Bulletin of Entomological Research, v.96, n.3, p.213-222, 2006. 
Mueller, D. K. A new method of using low levels of phosphine in combination with heat and carbon dioxide. In: Higley, E. J.; Whight, H. J.; Banks, H. J.; Champ, B. R. Stored product protection: proceedings of the 6th International Working Conference on Stored-product Protection. Canberra: CAB International, 1994. p.123-125.

Nation, J. L. Respiration. In: Nation, J. L. Insect physiology and biochemistry. Boca Raton: CRC Press LLC, 2002. Cap.12, p.371-380.

Noomhorm, A.; Sirisoontaralak, P.; Uraichuen, J.; Ahmad, I. Effects of pressurized carbon dioxide on controlling Sitophilus zeamais (Coleoptera: Curculionidae) and the quality of milled rice. Journal of Stored Products Research, v.45, p.201-205, 2009.

Ojimaa, N.; Yamashitab, M.; Watabec, S. Quantitative mRNA expression profiling of heat-shock protein families in rainbow trout cells. Biochemical and Biophysical Research Communications, v.329, n.1, p.51-57, 2005.

Pereira, A. M.; Faroni, L. R. D’A.; Sousa, A. H.; Urruchi, W. I.; Paes, J. L. Influência da temperatura da massa de grãos sobre a toxicidade do ozônio a Tribolium castaneum. Revista Brasileira de Engenharia Agrícola e Ambiental, v.12, n.5, p.493-497, 2008.

Pereira, A. M.; Faroni, L. R. D’A.; Sousa, A. H.; Urruchi, W. I.; Roma, R. C. C. Efeito imediato e latente da fumigação com ozônio na qualidade dos grãos de milho. Revista Brasileira de Armazenamento, v.32, n.2, p.100-110, 2007.
Pimentel, M. A. G.; Faroni, L. R. D’A.; Guedes, R. N. C.; Sousa, A. H.; Tótola, M. R. Phosphine resistance in Brazilian populations of Sitophilus zeamais Motschusky (Coleoptera: Curculionidae). Journal of Stored Products Research, v.45, n.1, p.71-74, 2009.

Pimentel, M. A. G.; Faroni, L. R. D’A.; Tótola, M. R.; Guedes, R. N. C. Phosphine resistance, respiration rate and fitness consequences in stored-product insects. Pest Management Science, v.63, n.9, p.876-881, 2007.

Pratt, S. J.; Reuss, R. Scrubbing carbon dioxide prevents overestimation of insect mortality in long-duration static phosphine toxicity assays. Journal of Stored Products Research, v.40, n.2, p.233-239, 2004.

SAS Institute. SAS/STAT User“s Guide, version 6.0, Cary: SAS Institute Inc., 1989.

Singh, A. K.; Lakhotia, S. C. Tissue-specific variations in the induction of Hsp70 and Hsp64 by heat shock in insects. Cell Stress and Chaperones, v.5, n.2, p.90-97, 2000.

Sousa, A. H.; Faroni, L. R. D’A.; Guedes, R. N. C.; Tótola, M. R.; Urruchi, W. I. Ozone as a management alternative against phosphine-resistant insect-pests of stored products. Journal of Stored Products Research, v.44, n.4, p.379-385, 2008.

SPSS. Sigma Plot user's guide, version 7.0 (revised edition), Chicago: SPSS Inc., 2001.

Trematerra, P.; Sciarretta, A. Spatial distribution of some beetles infesting a feed mill with spatio-temporal dynamics of Oryzaephilus surinamensis, Tribolium castaneum and Tribolium confusum. Journal of Stored Products Research, v.40, n.4, p.363-377, 2004. 